\title{
Effect of housing, initial weight and season on feedlot performance of steers in Iowa
}

\author{
H. Koknaroglü ${ }^{1 \#}$, D.D. Loy ${ }^{2}$ and M.P. Hoffman ${ }^{2}$ \\ ${ }^{1}$ Suleyman Demirel University, Isparta 32260, Turkey \\ ${ }^{2}$ Iowa State University, Ames, IA 50011, USA
}

\begin{abstract}
Feedlot information, submitted by Iowa cattle producers to the Iowa State University Feedlot Performance and Cost Monitoring Program, was examined to determine the effects of housing, initial weight and season interactions on beef steer performance. Feedlot information, consisting of 1225 pens of steers, contained information including starting and ending dates, cattle per pen, sex, housing type, days on feed, initial and sale weights, feed efficiency, proportion of concentrate in diets, average daily gain (ADG) and certain economic variables. Starting date on feed was assigned to seasons and, since the steers were fed an average for 160 days, an overlapping of seasons occurred. Thus, cattle started in feedlots in spring, autumn, summer and winter were finished in summer, spring, autumn and spring, respectively. Cattle started in spring, autumn, summer and winter were exposed to hot, cold and warm portions of the year, respectively, and were classified as hot, cold and warm season cattle. Cattle housed in open lots with overhead shelter had higher ADG than those housed in confinement and in open lots in the warm season. In general, cattle in confinement had lower daily dry matter intake (DDMI) than those housed in open lots and open lots with overhead shelter, regardless of season. Light cattle had higher ADG in the hot season, whereas, heavy cattle had higher ADG in the cold season. Heavy cattle housed in confinement had lower ADG than those housed in open lots with overhead shelter and in open lots. Heavy cattle were less efficient than light and intermediate weight cattle regardless of housing system. These results indicate that the time of year cattle are started on feed and selection of cattle with starting weights most adaptable to the housing system provided, may contribute to improved production efficiency.
\end{abstract}

Keywords: Feedlot cattle, performance, housing, season, initial weight, interaction, Iowa

${ }^{\#}$ Corresponding author. E-mail address: hayati@ziraat.sdu.edu.tr

\section{Introduction}

A main goal of cattle producers is to improve feed conversion and consequently profitability. Efficiency of growth is a function of metabolisable energy retained relative to that which is converted to heat (Robinson et al., 1986). Cattle, as homoeothermic animals, live in a dynamic environment and interact with it. Thus, the environmental conditions surrounding cattle dictate their maintenance energy requirement. In beef cattle production, feed costs represent a major portion of the total cost (Koknaroglu \& Hoffman, 2002) and a typical production system expends nearly $75 \%$ of total feed energy requirements for maintenance (Ames, 1987). Therefore, within economic constraints, optimal environmental conditions should be provided to cattle to express their full genetic potential. Proper housing provides one means of modifying stressful environmental conditions (Pusillo et al., 1990). Research comparing different housing systems showed that overhead shelter in open lots resulted in better growth performance and feed conversion (Muhamad et al., 1983; Koknaroglu et al., 2000; 2005), and cattle housed in confinement have poorer performance than cattle in open lots or open lots with overhead shelter. Performance of cattle in different housing systems showed fluctuations between seasons. Leu et al. (1977) reported a housing by season interaction. In feedlots, season and initial weight should be taken into consideration because Hicks et al. (1990) reported that daily dry matter intake (DDMI) of heavier cattle is depressed more in a hot environment, while DDMI of lighter cattle is depressed more in a cold environment. In order to increase the performance of cattle, the interaction of season, initial weight and housing should be known. Previous research has reported mainly on two-way interactions. The data used in this study enabled us to evaluate the effects of a three-way interaction between season, initial weight and housing on the average daily gain (ADG), DDMI and feed efficiency (FE) of feedlot cattle. 


\section{Materials and Methods}

Data used in this study consisted of feedlot information submitted by Iowa cattle producers to the Iowa State University Animal Science Extension Program. The Feedlot Performance and Cost Monitoring Program developed by Iowa State University Animal Science extension personnel provides the following information: starting date on feed, end of feeding period date, number of cattle in the pen, housing facility code ( 1 = confinement, 2 = partially open lot, 3 = open lot), days on feed, initial pay weight, final pay weight, feed conversion, average percent concentrate in diet, pay to pay average daily gain, percent death loss, feed cost per $45.4 \mathrm{~kg}$ gain, total cost, break even price, non-feed variable cost and non-feed fixed cost. Since this paper was an evaluation of feedlot performance, the economic data were not included in the analysis. Performance parameters evaluated, were ADG and FE provided by the cattle producers, and DDMI intake which was generated by computer by using the equation: DDMI = ADG $x$ FE.

In order to test for effects of season, it is important to characterize the climatic conditions in Iowa, USA. The average annual temperature is $8.3^{\circ} \mathrm{C}$ and represents average conditions in the autumn and spring seasons. In winter, temperature may get as low as $-26^{\circ} \mathrm{C}$ and in summer as high as $38^{\circ} \mathrm{C}$. Rainfall averages $813 \mathrm{~mm}$. per year and occurs throughout the year with precipitation in the winter being primarily in the form of snow. Due to temperature conditions, autumn and spring seasons can be quite muddy if cattle yards are unpaved. Accordingly, starting time on feed was used for assignment to seasons, and seasons were classified as Winter (December to February), Spring (March to May), Summer (June to August) and Autumn (September to November). Since the steers were fed for an average of 160 days, overlapping of seasons occurred and cattle starting in the feedlots in spring were finished at the end of summer. They were exposed to the hotter part of the year, which was classified as "hot season". Cattle started in autumn were finished at the end of spring and were exposed to the colder part of the year. This group was classified as "cold season". Cattle who started in winter and in summer were finished at the end of spring and autumn, respectively, and the parts of the year they were exposed to were intermediate in terms of temperature. These two periods were classified as the "warm season".

To analyze the effect of initial weight upon feedlot performance, the steers were allocated to three weight groups according to initial weights, viz. those less than $272 \mathrm{~kg}$ were classified as the light group, those between 272 - $363 \mathrm{~kg}$ the intermediate group and the steers heavier than $363 \mathrm{~kg}$ the heavy group. Three types of housing were compared: Confinement referred to cattle being completely under roof at all times. Partially open lot referred to cattle housed outdoors in pens with overhead shelter and open lot referred to cattle housed outdoors in pens without overhead shelter.

The average percentage concentrate in the diets was $83 \%$ (Table 1). One thousand two hundred and twenty five observations or pens of steers were used for the analysis. In some cases data from the same producer though from different years were included. In order to remain unbiased, the name of each farm or producer was assigned a number, which remained the same over the entire experimental period. To decrease the effect of initial weight and concentrate level on season by housing, season by initial weight and housing by initial weight interactions, some outlier observations were deleted, and concentrate level and initial weight were kept evenly distributed among interactions (Table 1). From 1988 to 1995 a total of 180,402 steers was fed in the 1225 pens, with an average of 147 steers per pen. No information was available on the age and background of the animals. At the onset of the feeding period the average weight of the steers was $348 \mathrm{~kg}$ and the animals were fed for an average of 160 days.

Although data from heifers, Holstein steers and bulls were available in the data set, data from steers only were used in this investigation. The reason is that steers far outnumbered the other sexes, and the distribution of other sexes in certain housing, initial weight or season categories would have caused a bias in the performance analyses. Data were reviewed and concentrate level and days on feed that were less than $50 \%$ and 50 days, respectively, were also removed from the data set.

Each observation was accepted as an independent observation even though some observations were obtained from the same farm. Data were analysed using the general linear model (SAS, 1999). An experimental unit was a pen of cattle. The PDIFF statement in the SAS program was used to test for significance between least squares means, interactions of season by initial weight, season by housing, and housing by initial weight. Type III sums of squares were used to test significance of main effects and interactions in the model. 
Table 1 Concentrate level, initial weight and number of pens according to season, initial weight and housing of the feedlot steers

\begin{tabular}{lccc}
\hline & $\begin{array}{c}\text { Concentrate level } \\
\text { (\% in diet) }\end{array}$ & $\begin{array}{c}\text { Initial weight } \\
(\mathrm{kg} \pm \text { s.d.) }\end{array}$ & Number of pens \\
\hline Season & & & \\
$\quad$ Cold & 83 & $348 \pm 52$ & 448 \\
$\quad$ Intermediate & 84 & $345 \pm 44$ & 576 \\
$\quad$ Hot & 84 & $352 \pm 37$ & 201 \\
Initial Weight & & & \\
$\quad$ Light & 81 & $293 \pm 12$ & 361 \\
$\quad$ Medium & 84 & $341 \pm 13$ & 399 \\
$\quad$ Heavy & 85 & $394 \pm 29$ & 465 \\
Housing & & $350 \pm 27$ & 208 \\
$\quad$ Confinement & 84 & $343 \pm 46$ & 332 \\
$\quad$ Overhead shelter & 82 & $348 \pm 51$ & 685 \\
$\quad$ Open & 84 & & \\
\hline
\end{tabular}

s.d. - standard deviation

\section{Results and Discussion}

In both the cold and warm seasons the heavier steers at the start of the feedlot feeding period had a higher mean ADG than the other weight groups ( $<<0.05$; Table 2$)$, and that of the intermediate and lighter groups did not differ $(\mathrm{P}>0.05)$ from each other. Even though the light cattle had numerically a higher ADG than the heavier ones in the hot season, differences between groups were not significant. The ADG of light cattle fed during the hot season of the year was higher $(\mathrm{P}<0.05)$ than those fed during the cold and warm seasons of the year. Temperatures during the different seasons of the year did not affect the ADG of the intermediate weight steers. Heavy cattle fed in the hot period of the year had lower ADG than the heavy ones fed during cold and warm periods of the year $(\mathrm{P}<0.05)$.

Table 2 Season $\mathrm{x}$ initial weight least squares means for average daily gain ( $\mathrm{kg} \pm$ s.e.) of feedlot steers

\begin{tabular}{lccc}
\hline \multirow{2}{*}{ Season } & \multicolumn{3}{c}{ Initial weight } \\
\cline { 2 - 4 } & \multicolumn{1}{c}{ Light } & Intermediate & Heavy \\
\hline Cold & $1.20^{\mathrm{a} 1} \pm 0.03$ & $1.23^{\mathrm{a} 3} \pm 0.03$ & $1.28^{\mathrm{b} 1} \pm 0.02$ \\
Warm & $1.20^{\mathrm{a} 1} \pm 0.02$ & $1.26^{\mathrm{b} 3} \pm 0.02$ & $1.29^{\mathrm{b} 1} \pm 0.02$ \\
Hot & $1.29^{\mathrm{c} 2} \pm 0.04$ & $1.26^{\mathrm{c} 3} \pm 0.03$ & $1.24^{\mathrm{c} 2} \pm 0.03$ \\
\hline
\end{tabular}

\footnotetext{
${ }^{\mathrm{a}, \mathrm{b}}$ Means with different superscripts in the same row differ $(\mathrm{P}<0.05)$

${ }^{\mathrm{c}}$ Means with common superscripts in the same row do not differ $(\mathrm{P}>0.05)$

${ }^{1,2}$ Means with different superscripts in the same column differ $(\mathrm{P}<0.05)$

${ }^{3}$ Means with common superscript in the same column do not differ $(\mathrm{P}>0.05)$

s.e. - standard error
}

As can be expected, the heavier the steers at the onset of the feedlot feeding period, the higher their DDMI $(\mathrm{P}<0.05$; Table 3). Light cattle fed in the hot season of the year tended $(\mathrm{P}=0.08)$ to have higher DDMI than light cattle fed during the warm season of the year. Intermediate weight cattle fed in the cold season had higher $(\mathrm{P}<0.05)$ DDMI than those fed in the warm season. Heavy cattle fed in the cold season had higher $(\mathrm{P}<0$ 05) DDMI than the same weight group fed in the warm and hot seasons, whereas the DDMI of those fed in the warm and hot seasons did not differ from each other.

In the cold season, the light cattle were more efficient than the heavier groups $(\mathrm{P}<0.01$; Table 4$)$. When the steers were fed in the warm season, the light and intermediate weight groups were more efficient than the heavy group $(\mathrm{P}<0.01)$. In the hot season $\mathrm{FE}$ decreased as initial cattle weight increased $(\mathrm{P}<0.01)$. The light steers fed in the hot season had a better $(\mathrm{P}<0.05)$ FE than those fed in the warm season, and tended $(\mathrm{P}=0.065)$ to have a better FE than those fed in the cold season. Intermediate weight cattle fed in 
the warm and hot seasons had a better $(\mathrm{P}<0.05) \mathrm{FE}$ than those fed in the cold season. Heavy cattle fed in the warm season had a better FE than those fed in the cold season $(\mathrm{P}<0.05)$ and had similar FE as cattle fed in the hot season $(\mathrm{P}>0.05)$.

Table 3 Season $x$ initial weight least squares means for daily dry matter intake ( $\mathrm{kg} \pm$ s.e.) of feedlot steers

\begin{tabular}{llll}
\hline \multirow{2}{*}{ Season } & \multicolumn{3}{c}{ Initial weight } \\
\cline { 2 - 4 } & \multicolumn{1}{c}{ Light } & \multicolumn{1}{c}{ Intermediate } & Heavy \\
\hline Cold & $8.87^{\mathrm{a} 1} \pm 0.13$ & $9.88^{\mathrm{b} 1} \pm 0.12$ & $10.63^{\mathrm{c} 1} \pm 0.11$ \\
Warm & $9.16^{\mathrm{a} 2} \pm 0.12$ & $9.71^{\mathrm{b} 2} \pm 0.11$ & $10.29^{\mathrm{c} 2} \pm 0.11$ \\
Hot & $9.32^{\mathrm{a} 2} \pm 0.18$ & $9.78^{\mathrm{b} 1,2} \pm 0.12$ & $10.22^{\mathrm{c} 2} \pm 0.13$
\end{tabular}

\footnotetext{
${ }^{\mathrm{a}, \mathrm{b}, \mathrm{c}}$ Means with different superscripts in the same row differ $(\mathrm{P}<0.05)$

${ }^{1,2}$ Means with different superscripts in the same column differ $(\mathrm{P}<0.05)$

s.e. - standard error
}

Table 4 Season $\mathrm{x}$ initial weight least squares means for the feed efficiency ( $\mathrm{kg}$ feed/kg gain \pm s.e.) of feedlot steers

\begin{tabular}{llll}
\hline \multirow{2}{*}{ Season } & \multicolumn{3}{c}{ Initial weight } \\
\cline { 2 - 4 } & \multicolumn{1}{c}{ Light } & Intermediate & Heavy \\
\hline Cold & $7.49^{\mathrm{a} 1,2} \pm 0.14$ & $8.24^{\mathrm{b} 1} \pm 0.14$ & $8.44^{\mathrm{b} 1} \pm 0.13$ \\
Warm & $7.72^{\mathrm{a} 2} \pm 0.13$ & $7.83^{\mathrm{a} 2} \pm 0.13$ & $8.12^{\mathrm{b} 2} \pm 0.12$ \\
Hot & $7.26^{\mathrm{a} 1} \pm 0.21$ & $7.90^{\mathrm{b} 2} \pm 0.14$ & $8.31^{\mathrm{c} 2} \pm 0.15$
\end{tabular}

\footnotetext{
${ }^{a, b, c}$ Means with different superscripts in the same row differ $(\mathrm{P}<0.01)$

${ }^{1,2}$ Means with different superscripts in the same column differ $(\mathrm{P}<0.05)$

s.e. - standard error
}

When considering the overlapping of seasons, it is evident from Table 3 that the heavy steers had lower DDMI at higher temperatures, and light steers had lower DDMI at lower temperatures, compared to the other groups. The intermediate weight group seemed to be less affected by season. This is in agreement with Hicks et al. (1990) who found that in Oklahoma, at elevated temperatures, heat depressed DDMI more in heavier than in lighter cattle and cold stress tended to depress DDMI more in lighter than in heavier cattle. The reason for heavier cattle to be more susceptible to elevated temperatures might be their smaller surface area relative to body weight and thus reduced ability to dissipate body heat. Young (1988) showed that the surface area in square metres of standing cattle does not increase linearly with an increase in body weight. He proposed the equation $\mathrm{A}\left(\mathrm{m}^{2}\right)=0.09 \times \mathrm{BW}^{0.67}$, where $\mathrm{A}\left(\mathrm{m}^{2}\right)$ is the surface area of cattle in square metres and BW is body weight. From this equation lighter weight cattle have a greater surface area relative to their body weight than heavier animals, thus giving them a higher heat dissipation potential at elevated temperatures than heavier cattle. Another reason for this could be that the higher producing animals, which consume more feed, create more metabolic heat, than slower growing animals. They would thus tend to be more susceptible to heat stress because animals must dissipate metabolic heat when there is a reduced thermal gradient between the body core and the environment (Mader, 2003).

Light weight cattle starting in the feedlots in autumn and thus exposed to the colder period of the year gained significantly less $(\mathrm{P}<0.05)$ than those starting in spring and were fed during the hotter period of the year. Although there is no indication this could be due to weaning stress and compensatory growth, springborn calves are likely to be weaned in the autumn and be placed in feedlots at this time. This would expose them to the cooler part of the year. Weaning stress and adjustment time required to adapt to a new diet could also be contributory factors to the poor performance of cattle starting in the feedlot in the autumn. Phillips et al. (1987) found that spring-born calves weaned in October at approximately eight months of age lost $15 \mathrm{~kg}$ or $7.9 \%$ of their weaning weight during the 24 -hour period following separation from their dams. A reason 
for cattle starting in spring to gain weight faster than those starting at other times of the year could be due to compensatory growth because these cattle were on a low energy diet in winter and then placed in the feedlots in spring on a high energy diet (Fox et al., 1972). However, they are also exposed to more favourable environmental conditions and an increasing daylight length (Mossberg \& Jonsson, 1996). Heavier cattle tended to gain less and have poorer FE when they are started in the feedlots in autumn and spring, and fed during hot and cold parts of the year, respectively. The reason for this could be a reduced DDMI in cattle fed in the hot season, and increased maintenance requirements of cattle fed in the cold season. Feed conversion of cattle fed in the cold season was lower $(\mathrm{P}<0.05)$ than those fed in the other seasons. Part of the reason for this could be higher thyroxine levels in the plasma causing an increase in rate of passage of food through the digestive tract, thus resulting in less exposure time for digesta to be digested (NRC, 1981; Young, 1981).

In the cold season, the ADG of cattle fed in the various housing systems did not differ (Table 5). Cattle fed during the warm season and reared in open lots with overhead shelter had higher ADG than those in confinement and in open lots $(\mathrm{P}<0.05)$. In this season cattle in the open lots also had higher ADG than cattle fed in confinement $(\mathrm{P}<0.05)$. In the hot season, cattle in open lots with overhead shelter had numerically higher gains than those in confinement or open lots $(\mathrm{P}>0.05)$. In the confinement group, season had no effect on ADG (P > 0.05). Cattle fed in open lots with overhead shelter and fed in the cold season had lower $(\mathrm{P}<0.05)$ ADG than those fed in the warm and hot seasons. The trend seen in open lots with overhead shelter was also evident in open lots, while cattle fed in the cold season had a lower $(\mathrm{P}<0.05)$ ADG than those fed in warm and hot seasons.

Table 5 Season $\mathrm{x}$ housing least squares means for average daily gain ( $\mathrm{kg} \pm$ s.e.) of feedlot steers

\begin{tabular}{llll}
\hline \multirow{2}{*}{ Season } & \multicolumn{3}{c}{ Housing } \\
\cline { 2 - 4 } & Confinement & Overhead shelter & Open \\
\hline Cold & $1.23^{\mathrm{a} 1} \pm 0.03$ & $1.25^{\mathrm{a} 2} \pm 0.03$ & $1.23^{\mathrm{a} 2} \pm 0.02$ \\
Warm & $1.19^{\mathrm{b} 1} \pm 0.03$ & $1.30^{\mathrm{c} 3} \pm 0.02$ & $1.26^{\mathrm{d} 3} \pm 0.02$ \\
Hot & $1.23^{\mathrm{a} 1} \pm 0.04$ & $1.30^{\mathrm{a} 3} \pm 0.03$ & $1.26^{\mathrm{a} 3} \pm 0.02$ \\
\hline
\end{tabular}

\footnotetext{
${ }^{\mathrm{a}}$ Means with common superscript in the same row do not differ $(\mathrm{P}>0.05)$

${ }_{b, c, d}$ Means with different superscripts in the same row differ $(\mathrm{P}<0.05)$

${ }^{1}$ Means with common superscript in the same column do not differ $(\mathrm{P}>0.05)$

${ }^{2,3}$ Means with different superscripts in the same column differ $(\mathrm{P}<0.05)$

s.e. - standard error
}

Table 6 Season $x$ housing least squares means for daily dry matter intake ( $\mathrm{kg} \pm$ s.e.) of feedlot steers

\begin{tabular}{llll}
\hline \multirow{2}{*}{ Season } & \multicolumn{3}{c}{ Housing } \\
\cline { 2 - 4 } & Confinement & Overhead shelter & Open \\
\hline Cold & $9.42^{\mathrm{a} 12} \pm 0.15$ & $9.91^{\mathrm{b} 3} \pm 0.13$ & $10.05^{\mathrm{b} 3} \pm 0.11$ \\
Warm & $9.30^{\mathrm{a} 1} \pm 0.13$ & $9.91^{\mathrm{b} 3} \pm 0.11$ & $9.95^{\mathrm{b} 3} \pm 0.11$ \\
Hot & $9.59^{\mathrm{a} 2} \pm 0.17$ & $9.77^{\mathrm{ab} 3} \pm 0.15$ & $9.95^{\mathrm{b} 3} \pm 0.12$
\end{tabular}

\footnotetext{
${ }^{\mathrm{a}, \mathrm{b}}$ Means with different superscripts in the same row differ $(\mathrm{P}<0.05)$

${ }^{1,2}$ Means with different superscripts in the same column differ $(\mathrm{P}<0.05)$

${ }^{3}$ Means with common superscript in the same column do not differ $(\mathrm{P}>0.05)$

s.e. - standard error
}

Cattle fed in cold and warm seasons and housed in confinement had lower DDMI than those housed in open lots with overhead shelter and in open lots $(\mathrm{P}<0.05$; Table 6$)$. In the hot season, cattle in confinement had lower DDMI than those in open lots $(\mathrm{P}<0.05)$ and had similar DDMI to cattle in open lots with overhead shelter $(\mathrm{P}>0.05)$. Cattle housed in confinement and fed during the warm season had lower DDMI than those fed in the hot season $(\mathrm{P}<0.05$; Table 6$)$ but did not differ from those fed in the cold 
season. Weather did not influence DDMI of cattle housed in open lots with overhead shelter and cattle in open lots.

Cattle fed during the cold season and housed in confinement were more efficient $(\mathrm{P}<0.05$; Table 7$)$ than the other groups. In the warm and hot seasons, cattle housed in open lots with overhead shelter were more efficient than those reared in open lots $(\mathrm{P}<0.05)$. Cattle housed in confinement and fed in cold, warm and hot seasons had similar FE ( $>$ > 0.05). Cattle housed in open lots with access to overhead shelter and in open lots, and fed during the cold season were less efficient than those fed during the warm and hot seasons $(\mathrm{P}<0.01)$.

Table 7 Season $\mathrm{x}$ housing least squares means for feed efficiency (kg feed/kg gain \pm s.e.) for feedlot steers

\begin{tabular}{llll}
\hline \multirow{2}{*}{ Season } & \multicolumn{3}{c}{ Housing } \\
\cline { 2 - 4 } & Confinement & Overhead shelter & Open \\
\hline Cold & $7.79^{\mathrm{a} 1} \pm 0.17$ & $8.09^{\mathrm{b} 2} \pm 0.14$ & $8.30^{\mathrm{b} 2} \pm 0.12$ \\
Warm & $7.91^{\mathrm{ab} 1} \pm 0.15$ & $7.74^{\mathrm{a} 3} \pm 0.13$ & $8.01^{\mathrm{b} 3} \pm 0.12$ \\
Hot & $7.87^{\mathrm{ab} 1} \pm 0.19$ & $7.58^{\mathrm{a} 3} \pm 0.17$ & $8.02^{\mathrm{b} 3} \pm 0.14$
\end{tabular}

\footnotetext{
${ }^{\mathrm{a}, \mathrm{b}}$ Means with different superscripts in the same row differ $(\mathrm{P}<0.05)$

${ }^{1}$ Means with common superscript in the same column do not differ $(\mathrm{P}>0.05)$

${ }^{2,3}$ Means with different superscripts in the same column differ $(\mathrm{P}<0.01)$

s.e. - standard error
}

As noted previously the overlapping of seasons should be considered when evaluating the effects of season on cattle feedlot performance. The ADG of cattle fed during the cold season in open lots and in open lots with overhead shelter was lower $(\mathrm{P}<0.05)$ than that of those fed during the warm and hot seasons in these facilities (Table 5). However, when in confinement, season did not affect ADG in the steers significantly. This is in agreement with Muhamad et al. (1983) who found that in Iowa, cattle fed in open lots and in open lots with overhead shelters gained weight faster when they started on feed in summer than in winter. However, cattle fed in confinement did not differ in terms of ADG regardless of when they started in the feedlots (Muhamad et al., 1983). When comparing the DDMI of cattle from the end of April to the beginning of October in Iowa, Ness (1980) found that cattle in open lots with overhead shelter had a higher DDMI than those fed in open lots or in confinement. This could be partially due to the restriction of animal movement when confined (Curtis, 1972). In the present study, when cattle were placed in the feedlots in the spring and fed during the hot season, the DDMI of cattle with overhead shelter was slightly higher than that of cattle kept in confinement. Furthermore, the DDMI of cattle that started in the autumn and fed in the cold season, was higher for open lot fed cattle than those in the other housing systems. A possible reason for cattle in open lots with overhead shelters having higher DDMI could be that the shelters prevent radiation and protects cattle from precipitation. On the other hand, the fact that confined cattle have a lower DDMI could be due to higher relative humidity and lower air movement in confinement, causing less heat dissipation from the animals' body surface. Hahn et al. (2001) demonstrated the benefits of using shade in areas with high temperatures and/or solar radiation. Effects of heat stress are not only dependent upon temperature and solar radiation, but also on humidity (Mader, 2003). Adjustments for humidity by using the temperature-humidity index have been adapted for use in the livestock safety index (Livestock Conservation Institute, 1970; NOAA, 1976; Hubbard et al., 1999). A combination of temperature with humidity in confinement affected DDMI of confinement fed cattle (Koknaroglu, unpublished data).

Cattle in open lots had a higher DDMI when they were started in feedlots in autumn than in the other seasons, possibly due to the lower environmental temperature in open lots, which could lead to higher thyroxine levels and, therefore, increased feed intake (Christopherson et al., 1976). The FE in confinement fed cattle did not differ across seasons, irrespective of whether they had access to overhead shelter or not. Feed efficiency tended to be better when average temperatures were higher. This is in agreement with NRC (1981) in which it was stated that digestibility for ruminants decreases by an average of $0.2 \%$ for each $1{ }^{\circ} \mathrm{C}$ decrease in ambient temperature. 
Cattle housed in confinement showed similar ADG regardless of initial weight ( $\mathrm{P}>0.05$; Table 8). Heavier cattle reared in open lots with overhead shelter had a higher ADG than the other weight groups $(P<0.05)$. Light and intermediate weight cattle had similar ADG regardless of type of housing $(P>0.05)$. Heavier cattle housed in open lots with overhead shelter had higher ADG than cattle housed in confinement and in open lots $(\mathrm{P}<0.05)$.

In all the housing systems, the DDMI of the heavier steers at the onset of the study was higher $(\mathrm{P}<0.01)$ than that of the steers with the lighter initial weights (Table 9). Lighter cattle had similar DDMI regardless of housing. Intermediate and heavy steers housed in confinement had lower DDMI than those housed in open lots and open lots with overhead shelter $(\mathrm{P}<0.01)$.

Table 8 Housing $\mathrm{x}$ initial weight least squares means for average daily gain (kg \pm s.e.) for feedlot steers

\begin{tabular}{llll}
\hline \multirow{2}{*}{ Housing } & \multicolumn{3}{c}{ Initial weight } \\
\cline { 2 - 4 } & Light & Intermediate & Heavy \\
\hline Confinement & $1.20^{\mathrm{a} 1} \pm 0.04$ & $1.24^{\mathrm{a} 1} \pm 0.03$ & $1.21^{\mathrm{a} 2} \pm 0.03$ \\
Shelter & $1.26^{\mathrm{b} 1} \pm 0.03$ & $1.26^{\mathrm{b} 1} \pm 0.03$ & $1.33^{1 \mathrm{c} 3} \pm 0.03$ \\
Open & $1.23^{\mathrm{b} 1} \pm 0.02$ & $1.25^{\mathrm{bc} 1} \pm 0.02$ & $1.27^{\mathrm{c} 4} \pm 0.02$ \\
\hline
\end{tabular}

\footnotetext{
${ }^{\mathrm{a}}$ Means with common superscript in the same row do not differ $(\mathrm{P}>0.05)$

${ }^{b, c}$ Means with different superscripts in the same row differ $(\mathrm{P}<0.05)$

${ }^{1}$ Means with common superscript in the same column do not differ $(\mathrm{P}>0.05)$

2,3,4 Means with different superscripts in the same column differ $(\mathrm{P}<0.05)$

s.e. - standard error
}

Table 9 Housing x initial weight least squares means for daily dry matter intake (kg \pm s.e.) for feedlot steers

\begin{tabular}{llll}
\hline \multirow{2}{*}{ Housing } & \multicolumn{3}{c}{ Initial weight } \\
\cline { 2 - 4 } & Light & Intermediate & Heavy \\
\hline Confinement & $8.97^{\mathrm{a} 1} \pm 0.20$ & $9.52^{\mathrm{b} 2} \pm 0.13$ & $9.83^{\mathrm{c} 2} \pm 0.14$ \\
Shelter & $9.12^{\mathrm{a} 1} \pm 0.13$ & $9.83^{\mathrm{b} 3} \pm 0.13$ & $10.64^{\mathrm{c} 3} \pm 0.12$ \\
Open & $9.26^{\mathrm{a} 1} \pm 0.12$ & $10.03^{\mathrm{b} 3} \pm 0.11$ & $10.67^{\mathrm{c} 3} \pm 0.11$
\end{tabular}

\footnotetext{
${ }^{a, b, c}$ Means with different superscripts in the same row differ $(\mathrm{P}<0.01)$

${ }^{1}$ Means with common superscript in the same column do not differ $(\mathrm{P}>0.05)$

${ }^{2,3}$ Means with different superscripts in the same column differ $(\mathrm{P}<0.01)$

s.e. - standard error
}

Light and intermediate weight cattle housed in confinement converted their feed more efficiently than the heavier cattle $(\mathrm{P}<0.01$; Table 10$)$. The FE of cattle in open lots decreased as initial weight increased $(\mathrm{P}<0.01)$. Lighter weight cattle were more efficient when they were housed in open lots with overhead shelter $(\mathrm{P}<0.01)$ than in the other housing systems. Intermediate weight cattle housed in confinement had better FE than cattle housed in open lots $(\mathrm{P}<0.01)$ and had similar FE to cattle in open lots with overhead shelter ( $\mathrm{P}>0.05)$. Heavy cattle housed in open lots were less efficient than those housed in confinement and in open lots with overhead shelter $(\mathrm{P}<0.01)$. In general, the light weight cattle were more efficient, irrespective of housing system.

These results showed that, in general, providing overhead shelter increased ADG. This was most pronounced in the heavier cattle (Table 8). This agrees with observations by Ralston et al. (1970) and Koknaroglu et al. (2005) that body size affects weight gain, viz. the higher the initial weight, the higher the increases in subsequent weight gains. However, the present results showed that the ADG of cattle in confinement tended to be lower than that of the intermediate weight cattle, an observation not in agreement with those of Ralston et al. (1970) and Koknaroglu et al. (2005). The reason seems to be a reduced FE 
(Table 10) because heavier cattle housed in confinement had higher DDMI than the other weight groups. This suggests that, in confinement, heavier cattle are affected more adversely than lighter cattle, which is possibly a function of the environmental factors associated with confinement housing and the thermal gradient of cattle with its environment. In general, cattle in open lots with overhead shelter tended to have a higher ADG than those under other housing conditions. This was most evident in heavier cattle, suggesting that heavier cattle are affected more by heat stress than lighter cattle (Table 2), and that shelter provides an additional mechanism to minimize heat stress in the summer.

Table 10 Housing $\mathrm{x}$ initial weight least squares means for feed efficiency (kg feed/kg gain \pm s.e.) for feedlot steers

\begin{tabular}{lllc}
\hline \multirow{2}{*}{ Housing } & \multicolumn{3}{c}{ Initial weight } \\
\cline { 2 - 4 } & Light & Intermediate & Heavy \\
\hline Confinement & $7.54^{\mathrm{a} 12} \pm 0.22$ & $7.84^{\mathrm{a} 1} \pm 0.15$ & $8.19^{\mathrm{b} 1} \pm 0.16$ \\
Shelter & $7.33^{\mathrm{a} 1} \pm 0.15$ & $7.94^{\mathrm{b} 1} \pm 0.15$ & $8.14^{\mathrm{b} 1} \pm 0.14$ \\
Open & $7.60^{\mathrm{a} 2} \pm 0.14$ & $8.19^{\mathrm{b} 2} \pm 0.13$ & $8.54^{\mathrm{c} 2} \pm 0.12$ \\
\hline
\end{tabular}

${ }^{a, b, c}$ Means with different superscripts in the same row differ $(\mathrm{P}<0.01)$

${ }^{1,2}$ Means with different superscripts in the same column differ $(\mathrm{P}<0.01)$

s.e. - standard error

\section{Conclusion}

The feedlot performance of lighter weight cattle was worse affected by the cold season, and that of the the heavier cattle by the hot season, compared to the other groups, respectively. Providing an overhead shelter proved to be especially effective in warm and hot seasons. Housing heavier cattle in confinement depressed daily gain, but the provision of overhead shelter in open lots improved ADG more than in the other weight groups. According to these results, cattle producers striving to improve production efficiency should consider the season in which cattle are placed to feedlots as well as the initial weight of the cattle relative to the type of housing system employed.

\section{References}

Ames, D.R., 1987. Effects of cold environments on cattle. Agri Practice 8, 26-29.

Christopherson, R.J., 1976. Effects of prolonged cold and the outdoor winter environment on apparent digestibility in sheep and cattle. Can. J. Anim. Sci. 56, 201-212.

Curtis, S.E., 1972. Air environment and animal performance. J. Anim. Sci. 35, 628-634.

Fox, D.G., Johnson, R.R., Preston, R.L. \& Dockerty, T.R., 1972. Protein and energy utilization during compensatory growth in beef cattle. J. Anim. Sci. 34, 310-318.

Hahn, G.L., Mader, T., Spiers, D., Gaughan, J., Nienaber, J., Eigenberg, R., Brown-Brandl, T., Hu, Q., Griffin, D., Hungerford, L., Parkhurst, A., Leonard, M., Adams, W. \& Adams, L., 2001. Heat wave impacts on feedlot cattle: Considerations for improved environmental management. In: Proc. $6^{\text {th }}$ Int. Livest. Environ. Symp., Am. Soc. Agric. Eng., St. Joseph, MI. pp. 129-130.

Hicks, R.B., Owens, F.N., Gill, D.R., Oltjen, J.W. \& Lake, R.P., 1990. Dry matter intake by beef steers: Influence of initial weight, time on feed and season of year received in yard. J. Anim. Sci. 68, 254265.

Hubbard, K.G., Stooksbury, D.E., Hahn, G.L. \& Mader, T.L., 1999. A climatological perspective on feedlot cattle performance and mortality related to the temperature-humidity index. J. Prod. Agric. 12, 650653.

Koknaroglu, H. \& Hoffman, M.P., 2002. Integration of pasturing systems for cattle finishing programs. 2002 Beef Research Report, A.S. Leaflet R1779. Iowa State University, USA.

Koknaroglu, H., Loy, D.D., Wilson, D.E., Hoffman, M.P. \& Lawrence, J.D., 2000. Factors affecting beef cattle performance and profitability in Iowa. J. Anim. Sci. 78 (Suppl 2), 36.

Koknaroglu, H., Loy, D.D., Wilson, D.E., Hoffman, M.P. \& Lawrence, J.D., 2005. Factors affecting beef cattle performance and profitability. The Professional Animal Scientist 21 (4), 286-296. 
LCI, 1970. Patterns of transit losses. Livestock Conservation Institute, Omaha, NE.

Leu, B.M., Hoffman, M.P. \& Self, H.L., 1977. Comparison of confinement, shelter and no shelter for finishing yearling steers. J. Anim. Sci. 44, 717-721.

Mader, T.L., 2003. Environmental stress in confined beef cattle. J. Anim. Sci. 81(E. Suppl. 2), E110-E119.

Mossberg, I. \& Jonsson, H., 1996. The influence of day length and temperature on food intake and growth rate of bulls given concentrate or grass silage ad libitum in two housing systems. J. Anim. Sci. 62, 233-240.

Muhamad, Y.B., Hoffman, M.P. \& Self, H.L., 1983. Influence of different ratios of corn and corn silage, housing systems and seasons on the performance of feedlot steers. J. Anim. Sci. 56, 747-754.

Ness, R.L., 1980. Effects of environmental temperature on feed consumption of yearling feedlot cattle. M.S. thesis, Iowa State University of Science and Technology, Ames, Iowa, USA.

NOAA. 1976. Livestock Hot Weather Stress. Operations Manual Letter C-31-76. NOAA, Kansas City, MO.

NRC. 1981. Effect of Environment on Nutrient Requirements of Domestic Animals. Natl. Acad. Press, Washington, D.C., USA.

Phillips, W.A., Juniewicz, P.E., Zavy, M.T. \& Von Tungeln, D.L., 1987. The effects of the stress of weaning and transit on performance and metabolic profile of beef calves of different genotypes. Can. J. Anim. Sci. 67, 991-999.

Pusillo, G.M., Hoffman, M.P. \& Self, H.L., 1990. Effects of placing cattle on feed at two-month intervals and housing on feelot performance and carcass grades. J. Anim. Sci. 69, 442-450.

Ralston, A.T., Davidson, T.P. \& Kennick, W.H., 1970. The effect of initial weight, time on feed and prefinishing environment upon feedlot performance of steers. Agr. Exp. Sta., Oregon Sta. Univ. Tech. Bul. 113, 1-19.

Robinson, J.B., Ames, D.R. \& Milliken, G.A., 1986. Heat production of cattle acclimated to cold, thermoneutrality and heat when exposed to thermoneutrality and heat stress. J. Anim. Sci. 62, 14341440.

SAS, 1999. Statistical Analysis Systems User's Guide ( $8^{\text {th }}$ ed.). SAS Institute Inc., Raleigh, North Carolina, USA.

Young, B.A., 1981. Cold stress as it affects animal production. J. Anim. Sci. 52, 154-163.

Young, B.A., 1988. Effect of environmental stress on nutrient needs. In: The Ruminant Animal: Digestive Physiology and Nutrition. Ed. Church, D.C., Waveland Press, Inc., Prospect Heights, IL. pp. 456-467. 